Mr. Calvert's dismissal of philosophy and his very incomplete summing up of imponderables invite comment because they are fundamental to what seem to be our differences. However, no more is needed than a reference to the remarks of another mathematician, Mr. Sadler, on pages 105 and 106 of Volume 15, No. I of this Journal, where, with authority, diplomacy and obvious understanding, he describes the place of mathematics in this field; I agree entirely with his views.

I am glad to see that Mr. Calvert is emphasizing the need to deal, not only with steady-bearing cases, but also with the close approaches. The latter lend emphasis to the point made in my last note (15, 104) that, to be successful, a system based on manœuvring directive must contain clear indications of the circumstances in which the mariner ceases to have freedom of choice and must follow the directive.

I shall be very interested to hear Captain Oudet's reaction to a conjunction between the Calvert plan of manœuvre and his own traffic structure; at present $(15,19,20)$ he sees the life of the Collision Regulations continuing.

\title{
Ocean Routing Charts
}

\author{
from Captain A. F. Dickson \\ (Shell Tankers, Ltd.)
}

Passenger and cargo liners sailing on regular routes follow tracks for a given voyage, taking account of the various seasonal conditions which may apply, and masters of these ships, with many years experience in a particular trade, can decide without great difficulty the most advantageous track for their ship when planning a voyage for a given time of year.

In the transport of oil, on the other hand, it is not common to employ ships on regular voyages, and the great majority of tankers are employed in world-wide trading, so that although a particular oil company may have a number of ships constantly voyaging on a particular route, a high degree of flexibility is maintained and ships are regularly changed from one route to another. This means that the tanker master is called upon to consider the requirements for optimum routing of his ship on any ocean voyage. Further, he is often given his orders with fairly short notice and, in some cases, he may have his destination changed either at the last moment or during the voyage, leaving him little time to consider the many factors which have to be taken into account when planning the best route for the voyage to be undertaken.

Bearing this in mind, some thought has been given to the way in which choice of route can be facilitated. It is suggested that when planning an ocean voyage, consideration has to be given to the following:

(1) The navigational limitations which apply to the ship in question. For example, when planning a voyage for a deep-draft tanker from Borneo to South Australia, it would have to be found out whether the depths in the Torres Straits were sufficient to allow the ship to use this passage. 
(2) The effects of ocean currents which are likely to be encountered on particular routes, taking account of seasonal changes.

(3) Weather conditions to be expected at the time of the voyage, with an assessment of the decrease in the ship's effective speed. In high latitudes attention has to be paid to ice conditions and perhaps to the incidence of fog.

(4) Thought has to be given to the international loadline zones, because it may be advantageous for a ship to deviate from the shortest ocean route when, by steaming a slightly longer distance, the ship can remain for a greater part of the voyage in a zone where less freeboard is permitted and therefore carry more cargo.

(5) Consideration has to be given to the bunker requirement for the voyage in question.

Now, the information required to enable a master to assess the various factors set out above is all available in a well-found ship, and at least all the following publications are relevant:

(a) Normal navigation charts and gnomonic charts showing the various greatcircle and rhumb-line tracks.

(b) Ocean current atlases.

(c) Meteorological atlases.

(d) The international loadline convention.

(e) Sailing directions.

(f) The Admiralty's Ocean Passages for the World.

In addition to the information required, many of these publications include a large wealth of detail which is not relevant to the routing requirements of a modern tanker. There is, for instance, the large amount of information given on suitable tracks for sailing ships and low-powered steamers. What the master of a modern ship requires is readily available data on the factors which affect his particular ship on any given voyage, and it is suggested that this can be facilitated by condensing the information available in the many publications listed above, without loss of value.

With this objective in mind, a suggestion was made to the Hydrographic Department of the Admiralty some time ago that they might consider the publication of suitable routing charts which would set out all the information required for a normal voyage. The Admiralty sought advice on the proposal from the Chart Users' Panel which has recently been inaugurated (this Journal, 14, 464). As might have been expected, the replies indicated that the main interest in routing charts of the type suggested lay with those concerned in the navigation of tankers. However, the interest shown was sufficiently encouraging for the Hydrographer to arrange a meeting to consider the matter further.

It was apparent at the meeting that the use of routing charts would not be restricted to tankers, and that they would be of interest to dry cargo ships as well. The point was made that the information would be useful for liners when cruising and, by adding sea temperature and humidity information on the chart, useful information could be provided for ships carrying dry cargo.

It was therefore decided that, as a first step, the Hydrographer would compile four sheets covering the North Atlantic, each representing a calendar month, at quarterly intervals. Each chart would show isobars and prevailing winds with panels giving information on the frequency of fog, visibility and incidence of 
gales of force 7 and over. The charts would also depict currents, great-circle tracks, loadline zones, ice limits, sea temperature and air humidity.

When the first four sheets have been compiled, the Hydrographic Department of the Admiralty have indicated their intention to inform the Chart Users' Advisory Panel with a view to discussing the display of information before printing.

\section{Interpreting Astro-position Lines at Sea}

$$
\text { from M. W. Richey }
$$

'THE mark of a good navigator is not so much his ability to obtain accurate information as his ability to evaluate and interpret correctly the information available to him.' So writes Captain Alton B. Moody, U.S.N.R. in the course of an interesting correspondence in the February number of the U.S. Naval Institute Proceedings. In the August 196 I number (page 132) Captain Robert Lee Rhoads, Jr., a shipmaster, suggests that the 'cartwheel' set of astro-sights, where four position-lines intersect each other at angles of about $45^{\circ}$, is inferior to the square where the position-lines intersect at approximately $90^{\circ}$, which gives a more reliable fix. One of Captain Rhoads's illustrations shows a case of a 4 -minute systematic error in a 'cartwheel' fix giving a position 6 miles in error, where the same error would have had no effect on the position interpolated from four sights taken at $90^{\circ}$ to each other.

In the February number, Commander Roger S. Strout, U.S.N.R., refers to Rear Admiral L. Tonta's paper in the Hydrographic Review for November 193 I, in which he describes the bisector method of analysing the plot. Tonta points out that systematic errors, which arise particularly from anomalies of the dip of the horizon, can assume large values and their certain elimination is the precondition of accurate fixing.

Commander Strout points out that the essential difference between Captain Rhoads's method of interpolation between position-lines where the pattern is opened out through systematic errors, and the one described by Admiral Tonta, is that the latter adds an arrow to each position-line pointing towards the star. Commander Strout goes on to say that the bisector method is too slow and messy for practical use on the plotting sheet, and suggests that since only one point on a bisector is normally used, an equal-distance method in which the observed position is assumed to be at an equal distance from each altitude position-line, can be substituted without loss of accuracy, and with a great gain in speed and clarity. Marking the arrows on the position-lines also enables the good sights to be distinguished from the bad ones when four sights are used. With three sights, blunders cannot be distinguished from systematic errors, but the study of a fourline plot will often reveal a blunder, though neither the magnitude nor the direction of the error will be indicated. With more than four sights-and Commander Strout suggests that a careful observer usually takes six-a blunder 